\title{
Influence of Rapid Solidification on the Thermophysical and Fatigue Properties of Laser Additive Manufactured Ti-6Al-4V Alloy
}

\author{
Olawale Samuel Fatoba, Esther Titilayo Akinlabi and \\ Mamookho Elizabeth Makhatha
}

Additional information is available at the end of the chapter

http://dx.doi.org/10.5772/intechopen.71697

\begin{abstract}
Modern industrial applications require materials with special surface properties such as high hardness, wear and corrosion resistance. The performance of material surface under wear and corrosion environments cannot be fulfilled by the conventional surface modifications and coatings. Therefore, different industrial sectors need an alternative technique for enhanced surface properties. The purpose of this is to change or enhance inherent properties of the materials to create new products or improve on existing ones. The most effective and economical engineering solution to prevent or minimize such surface region of a component is done by fiber lasers. Additive manufacturing (AM) is a breaking edge fabrication technique with the possibility of changing the perception of design and manufacturing as a whole. It is well suitable for the building and repairing applications in the aerospace industry which usually requires high level of accuracy and customization of parts which usually employ materials known to pose difficulties in fabrication such as titanium alloys. The current development focus of AM is to produce complex shaped functional metallic components, including metals, alloys and metal matrix composites (MMCs), to meet demanding requirements from aerospace, defense, and automotive industries.
\end{abstract}

Keywords: DLMD, solidification, fatigue, wear, Ti-6Al-4V alloy, microstructure, fiber laser, additive manufacturing

\section{Introduction}

Titanium is the ninth most abundant element on earth. It occurs as ilmenite, rutile and also present in titanates and iron ores. Titanium and its alloys are preferred choices for chemical, power generation, automobile, aerospace and airframe industries due to their excellent properties. 
Titanium has high strength and low density (40\% lower than steel). Titanium has many alloys with good properties. The most commonly used titanium alloy is the Ti-6Al-4V. It is also known as a workhorse. It is an alpha-beta alloy. Among other properties it possesses is that this alloy is heat treatable and has good hot forming qualities. However, its creep strength is not as good as the alpha alloys. Titanium and its alloys have low density, excellent combination of high specific ratio which is maintained at elevated temperatures, low modulus of elasticity and good corrosion resistance. Biocompatibility of the titanium alloy is excellent and makes it very good for biomedical applications due to its mechanical and corrosion properties. Titanium has a tenacious oxide which forms instantly upon exposure to air. This is the reason for its excellent corrosion resistance [1]. Titanium and it alloys are material of choice in a wide range of industrial applications owing to high strength-to-weight ratio, exceptional biocompatibility and corrosion resistance. However, the use of these materials is compromised due to high fabrication costs which are attributed to difficulty in the machining and loss of material during processing [2]. Estimate by research states that up to $50 \%$ of titanium cost are attributed to machining operations [3]. Fortunately, titanium is among the few privileged metallic materials that are fabricated by means of additive manufacturing which has the ability to fabricate high-quality parts with very little or no postmachining [4].

The application of laser surface modification to prolong the service life of engineering components exposed to aggressive environments has gained increasing acceptance in recent years and material processing by laser beams has been well established as an advanced manufacturing technology. The main mandate is the ability to precisely deposit a large amount of energy into a material over a short time range and in a spatially confined region near the surface. One of the major advantages of the laser as a tool for material processing is the ability to precisely control where in the material and at what rate energy is deposited. This control is exercised through the proper selection of laser processing parameters to achieve the desired material modification. Well known applications include the improvement of the wear resistance of diesel engine exhaust valves, the enhancement of the corrosion resistance of gas turbine blades and the repair of dies and inserts. The high-quality surface layers that can be produced by fiber laser only, make it a strategic technique. Surface engineering techniques especially by lasers are known to be cost-effective due to their precision and speed.

Material engineers continue to develop new and existing fabrication techniques in pursuit of improving or entirely replacing the conventional energy intensive, environmentally unfriendly and expensive methods [5]. Metal-based components are generally manufactured by subtractive and formative techniques; with the most recent additive fabrication which has been extensively explored since its development in the late 1980s [6]. The latter widens the perspective and boundaries of design as it provides new possibilities of fabricating complex geometries which are usually unattainable by traditional methods [7].

\section{Direct laser metal deposition}

The direct laser metal deposition (DLMD) is a recently developed technique for manufacturing solid parts, layer by layer, directly from powder. The process uses a high-power laser 
beam focused onto a metallic substrate to generate a molten pool to which a stream of powder is fed. This way, the material volume increases leading to the formation of a solid layer. The laser beam and powder nozzle are repeatedly scanned to accomplish a layered buildup of a solid part by additive manufacturing (AM). The key process parameters are laser power, scan speed, laser beam diameter, and powder feed rate. The parameters influence the thermal phenomena during the growth process of the solid part as well as the metallurgical and mechanical properties. This research will also describe the 2D \& 3D multi-physics models to describe the physical mechanism of heat transfer, melting and solidification that take place during and post laser-powder interaction. The transient temperature, geometrical features of the generated structures and thermal cycles will be simulated. The transient temperature is critically important for determining the thermal stress distribution and residual stress state in additively manufactured parts. According to Patterson et al. [8], thermal history generated by a laser beam during additive manufacturing governs the microstructure, properties, residual stress and distortion in fabricated components. In an attempt to overcome or reduce the evolution of residual stresses and the resultant of their unwanted artifacts, modeling and simulation of the additive manufacturing processes is a way to go instead of the time intensive and economic demanding trial and error methods. Additive manufacturing is a process which employs laser radiation to join materials layer by layer to make objects from 3D model data, which is reverse of subtractive manufacturing method. Hanzl et al. [9] stated that different fabrication techniques even when producing components from similar materials result in different properties. Authors further stated that additive manufacturing produces finer grains compared to conventional processes; this is attributed to rapid solidification which is a result of rapid heat conduction from the localized molten zone in direction of the dispersed cool surroundings. Furthermore, additive fabrication provides various benefits including elimination of forming equipment, high material use efficiency and the flexibility of producing customized parts which require very little or no post process machining which makes a direct contribution to the reduction of production cost and delivery time [10] (Figure 1).

The past decade has seen a rapid development in the range of techniques which are available to modify the surfaces of engineering components. This in turn has led to the emergence of the new field of surface modification. It describes the interdisciplinary activities aimed at tailoring the surface properties of engineering materials. An engineering material usually fails when its surface cannot effectively withstand the external forces or environment to which it is subjected. Serviceable engineering components not only rely on their bulk material properties but also on the design and characteristics of their surface. The surface of these components may require treatment, to enhance the surface characteristics. Surface treatments that cause microstructural changes in the bulk material include heating and cooling/quenching through induction, flame, laser, and electron beam techniques, or mechanical treatments [12]. The behavior of a material is therefore greatly dependent on the surface of a material, surface contact area and the environment under which the material must operate. Surface engineering can cause physical and chemical effects on the bulk material, some beneficial and some detrimental. For example, stresses which may exist in the protective material can create problems; however careful monitoring and research may limit these effects, to hopefully produce quality and serviceable engineering components. 


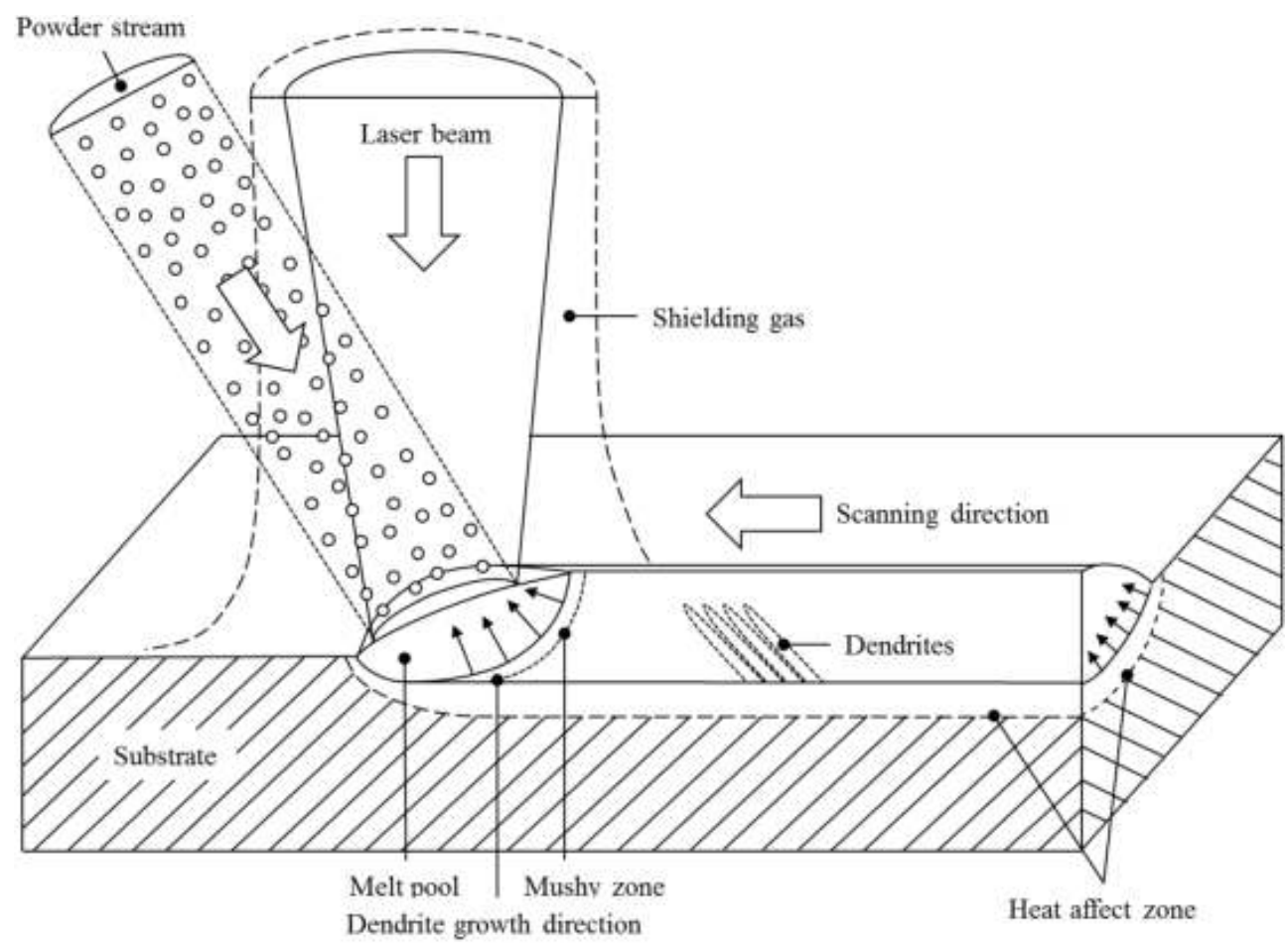

Figure 1. Schematic diagram illustrating the heat affected zone and melt zone created by laser surface melting [11].

The choice of a surface material with the appropriate thermal and sufficient resistance to wear and corrosion degradation is crucial to its functionality. The desired properties of surfaceengineered components are improved corrosion resistance through barrier or sacrificial protection, improved wear resistance and mechanical properties such as fatigue and toughness. The surface modification of metals, using high intensity lasers, accepts various methods in making use of the heat from the laser beam in enhancing the morphology and microstructure in order to achieve numerous metallurgical outcomes [13]. Laser surface modification of materials entails an extensive composition of additive and subtractive methods. Metals such as magnesium, titanium and aluminum blend extremely desired properties with light weight without a significant alteration of the bulk material. This is the footing for high demand of laser surface modification techniques [14]. There are many laser surface treatment techniques responsible for fabrication of highly corrosion-resistant metallic surfaces, where the major ones used are laser surface melting, laser cladding and laser surface alloying [15, 16].

Laser surface alloying (LSA) modifies the surface morphology and near surface structure of components and its alloys with perfect adhesion to the interface of the bulk steel. The distinctive advantages of the LSA technique for surface modification include the refinement of the grain size because of rapid quench rates and the generation of meta-stable structures with novel properties that are not feasible by competing methods $[17,18]$. With optimum laser processing parameters, 
a reliable coating that is free of cracks and pores can be produced on the matrix. LSA can rapidly provide a thick and crack-free layer in all instances with metallurgical bonds at the interface between the alloyed layer and the substrate [19]. In LSA, external alloying elements in form of powder (metal, alloy, ceramic, cermet or intermetallic) are introduced into the surface of a substrate, as pre-placed material or injected directly into the melt pool created on the substrate by a high-power laser beam. The melting of the substrate occurs rapidly only at the surface, while the bulk of the material remains cool, thus serving as an infinite heat sink.

The result of this is rapid self-quenching and resolidification of new alloy due to the large temperature gradients between the melted surface region and the underlying solid substrate. The evolution of a wide variety of microstructures as a result of the rapid cooling from the liquid phase is one of the consequences [20]. Hence, during laser alloying process, the synthesis of new alloy is possible by depositing a premixed ratio of elemental powders. Powders surfaced on new or worn working surfaces of components by LSA provides specific properties such as high abrasive wear resistance, erosion resistance, corrosion resistance, heat resistance and combinations of these properties. Consequently, improvements in machinery performance and safety in aerospace, automotive, can be realized by the method [21]. According to Poulon-Quintin et al. [22], laser beams, because of specific thermal characteristics induced by laser irradiation, can generate specific microstructures including metastable phases and nano-crystalline grains. Laser processing offers unique and significant quality and cost advantages over traditional techniques. These include high throughput speed, process compatibility, high process efficiency, low porosity and good surface uniformity. In addition, the rapid self-quenching in laser alloying results in a true metallurgical bond between the composite layer and the substrate, the formation of a nonequilibrium or amorphous phase as well as homogenization and refinement of the microstructure, all without affecting the bulk properties of the substrate [23-25].

\section{Overview on application and improved properties of laser deposited and additive manufactured Ti-6Al-4V alloy}

$\mathrm{Xu}$ et al. [26] investigated additive manufacturing ductile and strong Ti6Al4V by using selective laser melting through in situ martensite decomposition. Ti6Al4V powder was used to fabricate cubes and cylindrical bars by using a selective laser melting (SLM) facility with different process parameters. Different layer thicknesses were applied, 30, 60 and $90 \mu \mathrm{m}$ and the process was carried out in an argon atmosphere. The samples were then subjected to isothermal treatment for 2 hours at temperatures ranging from 350 to $930^{\circ} \mathrm{C}$. The tensile strength of the samples was evaluated and compared to Ti6Al4V manufactured by mill annealing and by solution treating and aging (STA). The microstructural analysis was completed by means of SEM and phase examination was carried out by X-ray diffraction. The results should that the finest columnar prior $\beta$ grains were found in the $30 \mu \mathrm{m}$ thick layer in comparison to the 60 and $90 \mu \mathrm{m}$ thicknesses; this was attributed to fast cooling condition. It was found that a smaller focal offset distance $(0-2 \mathrm{~mm})$ resulted in an ultrafine lamellar $(\alpha+\beta)$ microstructure, whereas a focal offset distance of $4 \mathrm{~mm}$ led to an acicular $\alpha^{\prime}$ martensitic microstructure. This led to the authors concluding that the transformation of martensite to 
ultrafine lamellar structure is possible by manipulating the process parameters of selective laser melting. The high yield strength and elongation failure of the SLM fabricated Ti6Al4V with ultrafine lamellar is comparable with STA Ti6Al4V and was better than that of millannealed Ti6Al4V, with results of $>1100 \mathrm{MPa}$ yield strength and $11.4 \%$ failure elongation. The heat treatment of the samples revealed that decomposition of $\alpha^{\prime}$ martensite into ultrafine lamellar took place from $400^{\circ} \mathrm{C}$. It was therefore concluded by the authors that additive manufacturing of Ti6Al4V by SLM can improve the properties.

Balla et al. [27] studied the microstructure of laser surface melted Ti6Al4V alloy as well as its mechanical and wear properties. Ti6Al4V alloy is extensively used for implants due to their exceptional corrosion resistance and biocompatibility; however, its poor hardness and low wear resistance limit the extent of application. A continuous-wave Nd:YAG laser was used to melt the surface of Ti6Al4V alloy sheet, $250 \mathrm{~W}$ and $400 \mathrm{~W}$ were used for single and double passes. Light microscopy, SEM and XRD were used to analyze the microstructure and phase of the melted regions. Ball-on-disk wear testing and Vickers microhardness tester were employed to establish the wear and microhardness. All results of the laser treated alloy were compared to as-received Ti6Al4V. The results showed that the sample treated with $400 \mathrm{~W}$ and was doubled passed exhibited the highest hardness and the largest grains size as compared to the other samples. An average increase of $15-22 \%$ in hardness was obtained by the laser surface melted alloy, with the hardness of the substrate being $358 \mathrm{HV}_{0.3}$ and the hardness of the treated samples ranging from $413 \mathrm{HV}_{0.3}$ to $438 \mathrm{HV}_{0.3}$. Results from both microstructural and phase analysis show that the as-received Ti6Al4V alloy had equiaxed $\alpha+\beta$ phase, while the laser surface melted regions displayed needle-like acicular $\alpha$ ( $\alpha^{\prime}$ martensite) embedded in prior $\beta$ matrix. The treated samples had a significantly increased relative concentration of $\alpha$ phase and a reduced $\beta$ phase in comparison to the substrate. The lowest wear rate was obtained by the both $250 \mathrm{~W}$ samples, with a wear rate of $3.38 \times 10^{-4} \mathrm{~mm}^{3} / \mathrm{Nm}$ in comparison with $6.82 \times$ $10^{-4} \mathrm{~mm}^{3} / \mathrm{Nm}$ of the untreated substrate. The authors therefore concluded that the improvement of Ti6Al4V alloy for in vitro application was possible by laser surface melting.

Brandl et al. [28] investigated the microstructure, morphology and hardness of Ti6Al4V blocks manufactured by wire-feed additive layer manufacturing (ALM). When components are built up layer by layer, it is referred to as direct manufacturing, rapid manufacturing or additive layer manufacturing. When comparing ALM to conventional manufacturing techniques, it is more cost efficient and less time consuming. A wire-feed system with a Nd:YAG rod laser and a wire feeder was used to deposit Ti6Al4V powder on Ti6Al4V alloy substrate. The blocks produced were 7 layers high and 7 beads wide. The samples were subjected to heat treatment after laser processing. The heat treatment completed included stress-relieving at $600^{\circ} \mathrm{C}$ for 4 hours and then cooled in the furnace and heating to $1200^{\circ} \mathrm{C}$ for 2 hours and followed by furnace cooling. After processing, the samples were prepared for microstructural analysis by cold mounting, polishing and etching. Light microscopy was used to examine the microstructure, a Vickers hardness tester was used to determine the hardness of the surface and energy dispersive X-ray microanalysis was carried out. The morphology of the block exhibited columnar prior $\beta$-grains and the microstructure found within the $\beta$-grains was martensite and basket-weave $\alpha$. The heat treatment of heating to $600^{\circ} \mathrm{C}$ for 4 hours and then furnace cooled did not change the morphology and microstructure but it did increase the hardness for 327 
$\mathrm{HV}_{0.5}$ to $342 \mathrm{HV}_{0.5}$. The samples subjected to heating to $1200^{\circ} \mathrm{C}$ for 2 hours and then cooled in a furnace had a lower hardness of $308 \mathrm{HV}_{0.5}$ due to change of the initial morphology to equiaxed prior $\beta$ grains.

Makuch et al. [29] studied the laser surface alloying of commercially pure titanium using carbon and boron. The use of titanium alloys ranges over many industries but the application in friction and wear conditions is limited due to their high tendency to adhesive wear, poor hardness and low wear resistance. Thermo-chemical processes such as boriding, nitriding and carburizing have been applied to steels and Ti alloys in order to improve the wear performance, but the disadvantages are that the thermal diffusion process requires high temperatures to achieve an acceptable layer thickness and the duration of the process is long. The material to be laser surface alloyed with boron and carbon was ring-shaped commercially pure titanium Grade 2. Three different pastes were produced for alloying; boron, boron and carbon, and carbon were mixed with polyvinyl alcohol to produce the pastes. The external surface of the cylinders was coated by the three different pastes and then the surface was re-melted with a continuous-wave $\mathrm{CO}_{2}$ laser. OPM and SEM were used to analyze the microstructure, XRD was used to examine the phases present, a Vickers hardness tester was used to determine the microhardness and a frictional pair was used to evaluate the abrasive wear of the layers. The greatest microhardness was achieved by the borided and borocarburized layers with 1250-1650 HV and 1200-1750 HV respectively, a hardness of 1000-1500 HV was obtained for the carburized layer. The increase in hardness was attributed to the formation of hard ceramic phases; $\mathrm{TiB}, \mathrm{TiB}_{2}$ and $\mathrm{TiC}$. It was found that of the coatings, the borocarburized layer exhibited the worst wear and friction performance and the laser borided sample had the best friction behavior and the laser-carburized had the best wear performance. It was concluded by the authors that laser alloying with boron and carbon will improve the wear resistance of titanium alloys.

Yang et al. [30] investigated synthesizing, microhardness and microstructure distribution of TiSi-C-N/TiCN composite coating fabricated on Ti6Al4V by laser cladding. TiN and TiCN coatings have been broadly used to extend the lifetime of medical and cutting tools due to their high hardness, good wear performance, biocompatibility, excellent corrosion resistance and affordable price. Although the properties of TiCN coatings are desirable, their thermal stability is not adequate and can be improved by adding $\mathrm{SiO}_{2}$ to the coating. A combination of titanium carbonitride and silica powders $\left(20 \% \mathrm{SiO}_{2}\right)$ was used to coat Ti6Al4V alloy by means of a YAG laser system. The laser beam scanning speed was varied at 1, 2, 3 and $4 \mathrm{~mm} / \mathrm{s}$ in order to examine how the properties will be affected. XRD was used to analyze the phases, SEM-EDS was used to characterize the microstructure and a microhardness tester with a load of $200 \mathrm{~g}$ and a dwelling time of $10 \mathrm{~s}$ was used to measure the microhardness. The phases that were obtained were $\mathrm{TiC}_{0.3} \mathrm{~N}_{0.7}, \mathrm{Ti}_{3} \mathrm{SiC}_{2}$ and $\mathrm{Ti}_{2} \mathrm{O}$. As the scan speed increased, the relative amount of $\mathrm{TiC}_{0.3} \mathrm{~N}_{0.7}$ decreased, amounts $\mathrm{Ti}_{3} \mathrm{SiC}_{2}$ increased by more than two times at a speed of $2 \mathrm{~mm} / \mathrm{s}$ from a speed of $1 \mathrm{~mm} / \mathrm{s}$ and increased gradually after that, and the amount of $\mathrm{Ti}_{2} \mathrm{O}$ was low at $1 \mathrm{~mm} / \mathrm{s}$, increased sharply at $2 \mathrm{~mm} / \mathrm{s}$ and then decreased by almost half for the following speeds. The microhardness of the coatings increased from $1005 \mathrm{HV}$ at $1 \mathrm{~mm} / \mathrm{s}$ to $1400 \mathrm{HV}$ at $3 \mathrm{~mm} / \mathrm{s}$ was reached, for $4 \mathrm{~mm} / \mathrm{s}$, the hardness reduced. The authors therefore concluded that laser cladding Ti6Al4V at $3 \mathrm{~mm} / \mathrm{s}$ will produced the most desired properties. 
Chen et al. [31] studied coaxial laser cladding on Ti6 Al4V alloy using $\mathrm{Al}_{2} \mathrm{O}_{3}-13 \% \mathrm{TiO}_{2}$ powders. For applications that require wear, erosion and corrosion resistance, $\mathrm{Al}_{2} \mathrm{O}_{3}-\mathrm{TiO}_{2}$ powders have been used in the plasma sprayed coatings, and the addition of $\mathrm{TiO}_{2}$ improves the wear resistance and toughness of $\mathrm{Al}_{2} \mathrm{O}_{3}$. Laser cladding of these powders has seldom been stated in open literature. $\mathrm{Al}_{2} \mathrm{O}_{3}-13 \% \mathrm{TiO}_{2}$ powders were laser cladded on Ti6Al4V alloy plate using Nd:YAG laser system. Optical microscopy and SEM were used to characterize the microstructure of the layer's cross-section and interface between the coating and substrate, EPMA was employed to analyze the element distribution of the cross-section and XRD was used to observe the phases present. After laser cladding, there was good metallurgical bonding between the coating and substrate and the coating exhibited no cracks. Three different regions of solidification microstructures were found from the bottom to the top surface of the melt pool. Region (I), which was closest to the substrate was found to be comprised of Ti columnar grains and uneven scattered ceramic particles. Region (II) consisted of fine equiaxed $\mathrm{Al}_{2} \mathrm{O}_{3}$ grains and region (III) showed $\mathrm{Al}_{2} \mathrm{O}_{3}$ grains that were coarse equiaxed and cellular with apparent isolation of TI and $\mathrm{V}$ elements. The ceramic phases that were present were $\alpha-\mathrm{Al}_{2} \mathrm{O}_{3}$, some $\mathrm{TiO}_{2}$ and $\mathrm{Al}_{2} \mathrm{TiO}_{5}$, and the cooling rate was too high to form sufficient $\gamma-\mathrm{Al}_{2} \mathrm{O}_{3}$. The authors therefore concluded that laser cladding of $\mathrm{Al}_{2} \mathrm{O}_{3}-13 \% \mathrm{TiO}_{2}$ powders on Ti6Al4V alloy was completed successfully.

Weng et al. [32] investigated the microstructures and wear properties of Co-based composite coatings fabricated on Ti6Al4V by laser cladding. Titanium alloys are used in the automotive, aerospace, weapons and chemical industries due to their good corrosion resistance and high specific strength. Surface modification processes such as carburizing, nitriding, thermal spraying, physical vapor deposition and chemical vapor deposition are used to improve their surface properties in order to expand their application. The authors targeted improving the wear and friction properties of Ti6Al4V alloy by laser cladding. The substrate used was Ti6Al4V and the powders used were $\mathrm{Co} 42, \mathrm{~B}_{4} \mathrm{C}, \mathrm{SiC}$ and $\mathrm{Y}_{2} \mathrm{O}_{3}$. Two mixtures of the powders were used for cladding; $\mathrm{Co} 42-20 \mathrm{~B}_{4} \mathrm{C}-7 \mathrm{SiC}-1 \mathrm{Y}_{2} \mathrm{O}_{3}$ (specimen 1) and $\mathrm{Co} 42-20 \mathrm{~B}_{4} \mathrm{C}-14 \mathrm{SiC}-1 \mathrm{Y}_{2} \mathrm{O}_{3}$ (specimen 2) in weight percentages. The powders were preplaced on the substrate and a cross flow $\mathrm{CO}_{2}$ laser system was used for laser processing in an argon atmosphere. The microstructure was examined by SEM, the phase constituents was determined by XRD, a Vickers hardness tester was used to establish the microhardness and a disk wear tester was used to assess the wear resistance. The results revealed that the coatings mainly consisted of $\gamma-\mathrm{Co} / \mathrm{Ni}$ solid solution and $\mathrm{CoTi}, \mathrm{CoTi}_{2}, \mathrm{TiC}, \mathrm{TiB}_{2}, \mathrm{TiB}, \mathrm{NiTi}, \mathrm{Cr}_{7} \mathrm{C}_{3}$ and $\mathrm{Ti}_{5} \mathrm{Si}_{3}$ phases. Specimen 1 was found to have a hardness of $1131 \mathrm{HV}_{0.2}$ while specimen 2 exhibited a hardness of $1314 \mathrm{HV}_{0.2}$ as compared to the hardness of the substrate, which was $350 \mathrm{HV}_{0.2}$. The wear tests showed that specimen had better wear performance. The authors concluded that the common wear mechanism was abrasive wear and the addition of $20 \% \mathrm{~B}_{4} \mathrm{C}, 7 \% \mathrm{SiC}$, and $1 \% \mathrm{Y}_{2} \mathrm{O}_{3}$ to the coating lead to excellent wear resistance. Too much $\mathrm{SiC}(14 \%)$ led to a coarser microstructure and the wear resistance is compromised as also reported by Fatoba et al. [33].

Carroll et al. [34] fabricated Ti6Al4V components by means of directed energy deposition additive deposition and examined the anisotropic behavior. Ti6Al4V has applications in the aerospace, medical device, sporting goods and petrochemical industries because of their high strength, low density and excellent corrosion resistance. Obtaining titanium is challenging 
hence the final products are costlier than their aluminum or steel counterparts. Powder-based additive manufacturing is a production technique in which a component is built on a workpiece by melting successive layers of metal feedstock. Additive manufacturing can produce a $3 \mathrm{D}$ component with complex parts and the same machine can be used to fabricate parts of different geometries. A Ti6Al4V plate was used as a substrate on which a Ti6Al4V cruciform was fabricated. A 2-kW laser was used to manufacture the laser build in an argon atmosphere. Tensile tests were conducted with a screw-actuated test frame, OPM was used to observe the microstructures and SEM was used to examine the fracture surface from the tensile tests and results were compared with those obtained with wrought Ti6Al4V. The yield strength of the additive manufactured was found to be $959 \pm 22 \mathrm{MPa}$ as compared to that of the wrought baseplate, which was established to be $973 \pm 8 \mathrm{MPa}$ and the ultimate tensile strength was determined to be $1064 \pm 23 \mathrm{MPa}$ for the additive manufactured versus $1050 \pm 8 \mathrm{MPa}$ of the wrought alloy. The authors concluded the mechanical properties of the additive manufactured part proportionate to those of the wrought material without any heat or pressure treatment after fabrication.

Gong et al. [35] examined how defects influenced the mechanical properties of Ti6Al4V parts manufactured by electron beam melting and selective laser melting. Additive manufacturing (AM) fabricates components from 3D CAD data, layer upon layer. The two most common AM processes based on powder-bed fusion are selective laser melting (SLM) and electron beam melting (EBM). The mechanical behavior of AM components can turn out greatly different from those that were manufactured conventionally due to their layered microstructure. The powers used were Ti6Al4V powders, the powder used for EBM was coarser $(73 \mu \mathrm{m})$ and the one used for SLM $(30 \mu \mathrm{m})$. Cylindrical bars were manufactured using both process and the parameters were varied for both processes. OPM was used to characterize the microstructure, the hardness was evaluated by a Rockwell C-Scale tester, tensile tests were completed using a tensile testing machine and fatigue tests were also conducted. The results showed that during SLM, defects were formed due to a low energy input and they caused the mechanical properties to be poor. Defects were also found in specimens that were fabricated with an excessive energy but they were not as detrimental as those produced by a lower energy. Large defects were found in EBM if the procedure used deviated from the optimum process parameters, which in turn led to poor mechanical properties. It was found that the microstructure formed depend mainly on the cooling rate rather than the defect generation as also reported by Makhatha et al. [36]. SLM and EBM-produced Ti6Al4V samples with comparable fatigue strength, tensile ductility and hardness but SLM produced slightly higher yield and tensile strengths.

Chikarakara et al. [37] worked on the high-speed laser surface modification of Ti6Al4V. The low density, high strength to weight ratio and biocompatibility affords Ti6Al4V application in biomedical engineering. However, wear and corrosion occurs when exposed to harsh conditions like the human due to some poor surface properties. When metallic ions are released and accumulate in the human body, discoloration of the nearby tissue will occur, or inflammatory reactions that lead to pain and osteolysis. The mechanical and tribological properties of titanium and its alloys are known to be improved by laser surface modification. Laser surface modification can serve multiple roles; its makes the surface more resistant to corrosion and wear, hardens the surface alloy, makes the surface more bioactive and stimulates bone growth 
because of an enhancement in wettability. $\mathrm{A} \mathrm{CO}_{2}$ continuous wave was used to irradiate Ti6Al4V alloy. The laser parameters were varied; the laser powers used were 100, 130 and $170 \mathrm{~W}$, irradiances applied were $15.72,20.44,26.72 \mathrm{~kW} / \mathrm{m}^{2}$, scanning speeds of 2500, 3750 and $5000 \mathrm{~mm} / \mathrm{in}$ and residence time of 2.16, 1.44 and $1.08 \mathrm{~s}$. OPM and SEM were used to observe the microstructures, surface roughness was evaluated by a stylus profilometer, XRD was used to identify phase constituents and microhardness was determined with the aid of a Vickers hardness tester. The results showed that the surface roughness of the samples decreased when the irradiance and residence time increased. XRD showed that after laser processing, the $\alpha$-Ti phase changed into an acicular structure cased within the aged $\beta$ matrix. The highest microhardness was obtained with the combination of the highest irradiance and lowest residence time, which was $760 \mathrm{HV}$ as compared to $460 \pm 13 \mathrm{HV}$ of the as-received alloy.

Yang et al. [38] investigated the corrosion behavior of additive manufactured Ti6Al4V alloy in $\mathrm{NaCl}$ solution. Because of the combination of low density, excellent strength, high biocompatibility and high fracture toughness, Ti6Al4V alloy is used in the marine, aerospace, energy and medical implant fields. Ti6Al4V alloy specimens produced by selective laser melting (SLM), selective laser treatment followed by heat treatment (SLM-HT), and wire and arc additive manufacturing (WAAM) had their microstructures observed and their electrochemical behaviors were tested. The heat-treated samples were heated to two different temperatures; namely $750^{\circ} \mathrm{C}$ (SLM-HT1) and $1020^{\circ} \mathrm{C}$ (SLM-HT2). A standard three-electrode electrochemical cell was used to evaluate the corrosion performance of the samples, OPM and SEM were utilized for microstructural examination and XRD was used to identify the phases present in the sample after they were laser processed. Microstructural analysis revealed that the SLM sample had comprised of $\alpha^{\prime}$ martensites within columnar $\beta$ grains. In SLMHT1, the martensites decomposed into a fine lamellar combination of $\alpha$ and $\beta$ phases inside the columnar prior $\beta$ grains. However, SLM-HT2 exhibited coarse $\alpha$ and $\beta$ phases and no columnar prior $\beta$ grains. WAAM consisted of fine $\alpha$ lamellae in $\alpha+\beta$ matrix. The electrochemical tests showed that the best corrosion resistance was obtained by SLM-HT1, followed by WAAM, SLM-HT2 and lastly SLM. The leading form of corrosion failure for the samples was pitting corrosion. It was therefore concluded by the authors that the heat treatment of SLM samples can improve the corrosion behavior as also reported by Popoola et al. [39].

Farayibi et al. [40] studied laser deposition of Ti6Al4V wire with WC powder for functionally graded components. Titanium alloys are used in the chemical, oil and gas, petrochemical, and ground transport industries because of their corrosion and fatigue resistance, high strength to weight ratio, ductility and toughness. The tribological properties are poor due to low hardness and high friction coefficients and therefore limit their applications abrasive and sliding wear conditions. Ti6Al4V wire and WC powder were deposited on Ti6Al4V alloy substrate by means of a 2-kW ytterbium-doped continuous-wave fiber laser. Other process parameters were kept constant while the powder feed rate was varied. The parameters were set to a power of $1800 \mathrm{~W}$, a transverse speed of $172 \mathrm{~mm} / \mathrm{min}$, wire feed rate of $800 \mathrm{~mm} / \mathrm{min}$ and the powder rates used were $10,15,20,25,30$ and $40 \mathrm{~g} / \mathrm{min}$. Vickers hardness tests were done on the surfaces of the samples, SEM was used to characterize the microstructure and XRD was employed to identify the phases present. The increase in the powder feed rate led to a decrease in the clad width and an increase in the height. It is important that this effect be understood for proper control of volumetric addition. The phases found in all the cladded samples were WC, W, TiC and $\beta$-TiC. The hardness 
increased with the increase in powder feed rate. An average range of $600-1030 \mathrm{HV}_{0.2}$ was found for rates with arrange of $10-40 \mathrm{~g} / \mathrm{min}$, which is a significant improvement from the hardness of the substrate $(350 \mathrm{HV})$. The increase in hardness was attributed to the presence of $\mathrm{W}$ and TiC precipitates.

Mahamood et al. [41] examined the effect of laser power on the microhardness and microstructure during laser metal deposition of Ti6Al4V. The most commonly produced titanium alloy, Ti6Al4V, is commonly used in the aerospace industry. Titanium and its alloys are generally difficult to machine and the high temperatures and galling caused by the interaction of the tool and alloy leads to a shortened lifespan for the tool. Additive manufacturing is a technique of processing a material by adding the material in a layer by layer manner. Laser metal deposition is an additive manufacturing method achieved by feeding a powder into a melt pool formed by a focused laser beam on a substrate. A $4.4 \mathrm{~kW}$ fiber Nd-YAG laser was used to deposit Ti6Al4V powder on a Ti6Al4V substrate. The scanning speed used was $0.005 \mathrm{~m} / \mathrm{s}$, the powder feed rate was kept constant at $1.44 \mathrm{~g} / \mathrm{min}$ and the laser powers used were $0.8,1.2,1.6,2.0,2.4,2.8,3.0 \mathrm{~kW}$.
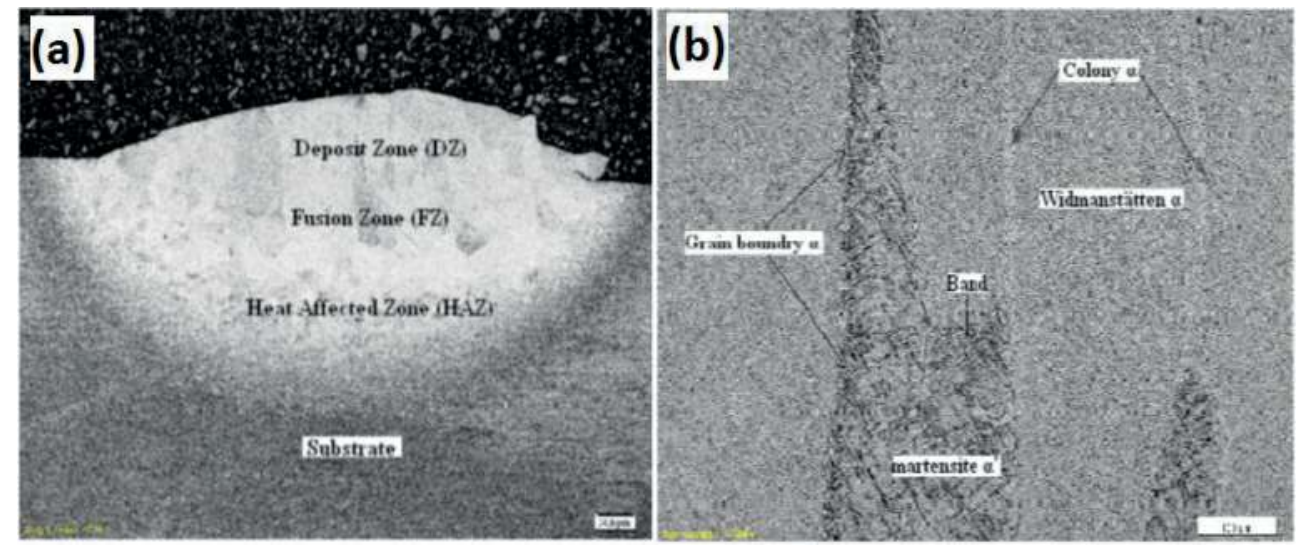

Figure 2. (a) Morphology of Sample A showing the different zones and (b) microstructure of the fusion zone of Sample G showing different $\alpha$ grains [41].

\begin{tabular}{lllll}
\hline Sample designation & Laser power $(\mathbf{k W})$ & Scanning speed $(\mathrm{m} / \mathbf{s})$ & Powder flow rate $(\mathrm{g} / \mathrm{min})$ & Gas flow rate $(\mathbf{l} / \mathbf{m i n})$ \\
\hline A & 0.8 & 0.005 & 1.44 & 4 \\
B & 1.2 & 0.005 & 1.44 & 4 \\
C & 1.6 & 0.005 & 1.44 & 4 \\
D & 2.0 & 0.005 & 1.44 & 4 \\
E & 2.4 & 0.005 & 1.44 & 4 \\
F & 2.8 & 0.005 & 1.44 & 4 \\
G & 3.0 & 0.005 & 1.44 & 4 \\
\hline
\end{tabular}

Table 1. Processing parameters [41]. 
OPM was used to study the microstructure of the samples and the microhardness was evaluated by a Vickers hardness tester with a load of $500 \mathrm{~g}$ and a dwelling time of $5 \mathrm{~s}$. the tests displayed that as the laser power increases, the microstructure of the heat affected zone became finer and the globular primary alpha phase became coarser. When the power increased, the microstructure change from fine martensite to thick martensite. The microhardness of the samples was found to increase with the increase in laser power. The authors therefore concluded that increasing the laser power of Ti6Al4V laser deposition will improve the properties (Figure 2, Table 1).

\section{Overview on the rapid solidification, surface and fatigue properties of additive manufactured Ti-6Al-4V alloy}

Rafi et al. [42] compared the mechanical properties and microstructures of Ti6Al4V components manufactured by electron beam melting and selective laser melting. Electron beam (EBM) and selective laser melting (SLM) are powder-bed fusion method of additive manufacturing used to produce metallic parts. SLM and EBM are advantageous over other conventional methods due to the freedom to manufacture complex shapes, elimination of expensive tooling and optimum material usage. SLM uses a laser heat source and its main process parameters are scan velocity, laser power, layer thickness and hatch spacing. EBM utilizes an electron beam to melt the powder layers. Ti6Al4V parts were fabricated using an SLM machine and an EBM machine by using Ti6Al4V powder. After manufacturing, the samples were taken for microstructural characterization by means of OPM and SEM. Phase composition was evaluated by XRD, hardness was determined by using a Rockwell hardness tester, tensile test were done at room temperature by means of a tensile testing machine and a fatigue testing machine was used to complete the fatigue tests. The surface finish of the parts showed that the EB samples had a rougher surface. The microstructure observed for the SL-produced parts consisted in martensitic $\alpha^{\prime}$ microstructures while EBM-produced samples resulted in an $\alpha$ phase while the $\beta$ phase separating the $\alpha$ lamellae. The highest tensile strength was obtained by the SLM-produced parts and the EBMparts had higher ductility. The high strength was caused by the presence of martensitic $\alpha^{\prime}$ microstructure in the SLM samples, while the lamellar $\alpha$ phase led to the high ductility. The lamellar phase in the EBM-produced parts resulted in a fatigue limit of $340 \mathrm{MPa}$ and the SLM sample reached $550 \mathrm{MPa}$. The authors concluded that the selection of the additive manufacturing process will depend on the application but both methods exhibited excellent mechanical properties (Figure 3, Table 2).

Vrancken et al. [43] examined the microstructure and mechanical properties of heat-treated Ti6Al4V alloy produced by selective laser melting. Selective laser melting (SLM) is one of additive manufacturing techniques which has advantages over conventional methods, such as a high level of flexibility, near net shape production, reduced production steps and high material use efficiency. Ti6Al4V powder was used as a base powder for selective melting processing and it was hot forged and mill annealed. SLM was done with an SLM machine equipped with SMYb:YAG fiber laser, with a laser power of $250 \mathrm{~W}$ and a scanning speed of $1600 \mathrm{~mm} / \mathrm{s}$. The samples were heat treated in a vertical tube furnace and then three different cooling methods were employed. Furnace cooling was done by turning the furnace off, air 

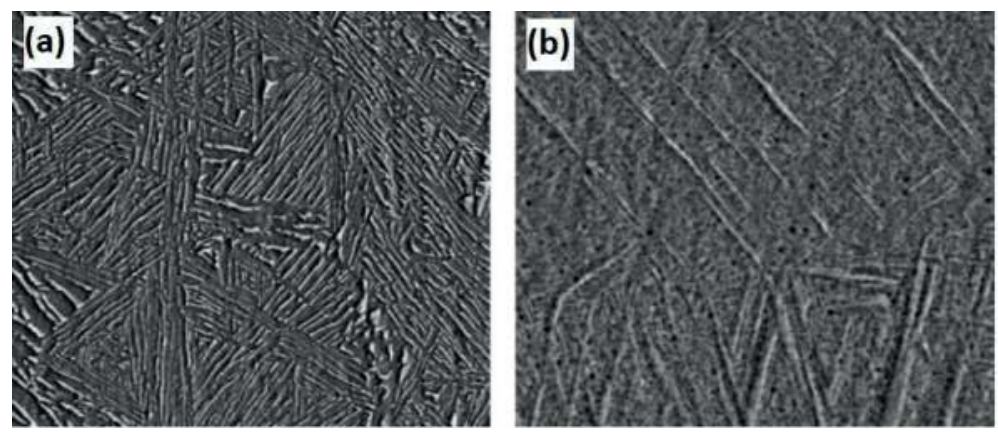

Figure 3. SEM images of (a) showing Widmanstatten structure in EBM-produced Ti-6Al-4V sample and (b) SLMproduced Ti-6Al-4V alloy sample [42].

\begin{tabular}{llll}
\hline & $\begin{array}{l}\text { Stress at yield (offset 0.2\%), } \\
\text { MPa }\end{array}$ & $\begin{array}{l}\text { Ultimate tensile stress, } \\
\text { MPa }\end{array}$ & $\begin{array}{l}\text { Strain at break, } \\
\%\end{array}$ \\
\hline EBM (vertically built and machined) & 869 (SD: 7.2) & 928 (SD: 9.8) & 9.9 (SD: 1.7) \\
SLM (vertically built and machined) & 1143 (SD: 30) & 1219 (SD: 20) & 4.89 (SD: 0.6) \\
\% Increase & 31 & 31 & -50 \\
EBM (horizontally built and machined) & 899 (SD: 4.7) & 978 (SD: 3.2) & 9.5 (SD: 1.2$)$ \\
SLM (horizontally built and machined) & 1195 (SD: 19) & 1269 (SD: 9$)$ & 5 (SD: 0.5$)$ \\
$\%$ Increase & 33 & 30 & -47 \\
$\begin{array}{l}\text { ASM handbook (Ref. [15]) (cast and } \\
\text { annealed) }\end{array}$ & 885 & 930 & \\
\hline
\end{tabular}

SD: standard deviation.

Table 2. Tensile results for SLM-produced and EBM-produced Ti-6Al-4V alloy samples [42].

cooling at room temperature and water quenching. The heat treatment was performed on Ti6Al4V with $\alpha^{\prime}$ microstructure, when heated, $\alpha$ phase was found to precipitate at the boundaries of $\alpha^{\prime}$. At the maximum temperatures below $\beta$ transus, grain growth was prevented by the mixture of $\alpha$ and $\beta$ phases formed. Microstructural revealed that for furnace cooling, the $\beta$ grains altered to lamellar $\alpha+\beta$ phases, air cooling resulted in the $\beta$ grains forming $\alpha$-Widmanstätten clusters and water quenching caused the $\beta$ grains to change into $\alpha^{\prime}$ martensite. SLM samples had higher ultimate tensile strength and yield strength than the substrate. The best mechanical properties were produced by furnace cooling. It was therefore concluded that the mechanical properties depend on the heat treatment performed (Figure 4).

$\mathrm{Hu}$ et al. [44] studied how laser texturing of Ti6Al4V affected its tribological behavior. Titanium and its alloys have industrial and biomedical applications because of their excellent mechanical and chemical properties. Their applications are limited by their poor tribological performance; this is caused by their severe adhesive wear, high friction coefficients and sensitivity to fretting wear. Surface texturing has been introduced into a sliding contact surface and 

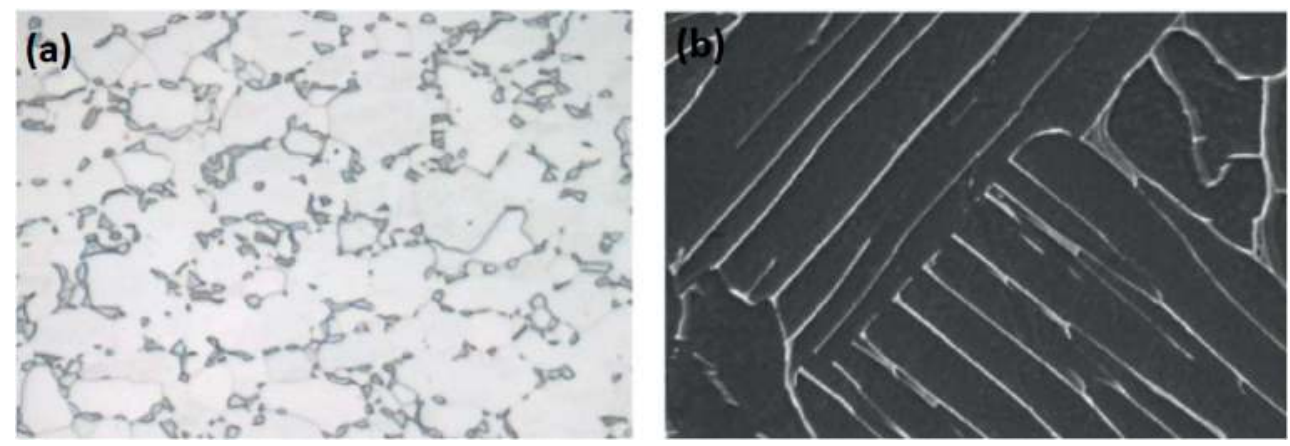

Figure 4. Microstructures of (a) the reference material (b) Ti-6Al-4V alloy produced by SLM after heat treatment [43].

was reported to remarkably affect the tribological properties. A Nd:YAG laser system was used to texture Ti6Al4V blocks and three different dimple diameters were fabricated; 45, 160 and $300 \mu \mathrm{m}$ and the depth was $25 \mu \mathrm{m}$ for all diameters. The surfaces of the textured and untextured samples were observed using a scanning electron microscope and an optical surface profiler, the microhardness was determined by means of a Vickers hardness tester and the friction tests were done with a pin-on-disk tribometer with the presence of a low viscosity oil lubricant. The hardness tests showed that of the textured and untextured samples was found to be the same, at a hardness of $295 \pm 15 \mathrm{HV}_{100}$. The friction test results showed that at a lower load $(2 \mathrm{~N})$, the friction coefficient of the textured samples was lower than that of the untextured Ti6Al4V, and the lowest coefficient was obtained by the $160 \mu \mathrm{m}$ dimples. However, at a higher load $(10 \mathrm{~N})$, the friction coefficients of the samples were generally the same. The authors concluded that dimple texture results in a lower friction coefficient and the best dimple diameter for friction reduction was $160 \mu \mathrm{m}$.

According to Gong et al. [45] additive manufactured parts are subject to inclusion of defects which negatively affects the materials mechanical properties, development of these artifacts is dependent on the choice of process parameter. Authors reported the defects generation mechanism of Ti-6Al-4V parts fabricated by selective laser melting (SLM) and electron beam melting (EBM) at varied process parameters. The results revealed a significant effect of energy input on defect generation on both the above-mentioned processes. However, different defect generation mechanism was observed when excessively high or low power density was used. In SLM, the use of high energy density leads to over-melting of powders and the vaporization of the melt pool result in defects generation. Whereas for EBM processes no bubbles or pores were observed, this was attributed to the ability of autonomously avoiding over-melting and evaporation. In conclusion, it was pointed out that the choice of process parameters governs the generation of defect. Fatoba et al. [46] and Aigbodion et al. [47] also agreed that optimizing process parameters are very necessary in avoiding cracks and pores.

Hrabe et al. [48] investigated the effects of residual stresses and internal defects (pores and voids) on fatigue performance of Ti- $6 \mathrm{Al}-4 \mathrm{~V}$ fabricated by electron beam melting. The fatigue properties of the as-fabricated, stress-relieved and the hot isostatic pressed (HIPed) samples were comparatively studied. The results obtained displayed insignificant residual stress in all 
samples which was attributed to high process temperatures of over $600^{\circ} \mathrm{C}$. The chemical compositions of all samples were unchanged, with only fatigue strength of HIPed being the different than in other conditions. However, the minimal microstructural coarsening, reduced porosity/void density and an increase in fatigue strength were observed in HIPed samples. It was concluded that voids were the initiation sites for the fatigue crack, which meant reducing their frequency and density plays a role in improving fatigue strength (Figures 5 and 6).

Cunningham et al. [49] investigated the effect of processing parameters on porosity of electron beam melted Ti-6Al-4V. The fatigue properties of a material are affected by porosity; these are points of weakness where cracks are initiated. Synchrotron-based X-ray microtomography characterization was carried out to determine the pore size, shape and spatial distribution of samples fabricated at various process conditions. The average diameter of all present pores was found to be less than 10 microns. However, some pores of about 50 microns in size were present at the surface of the samples of large melt pools. The volume of spherical pores which are associated with trapped gases displayed decrease with decrease in speed function. The authors further pointed out that the decrease in melt pool area significantly increases the lack of fusion porosity.

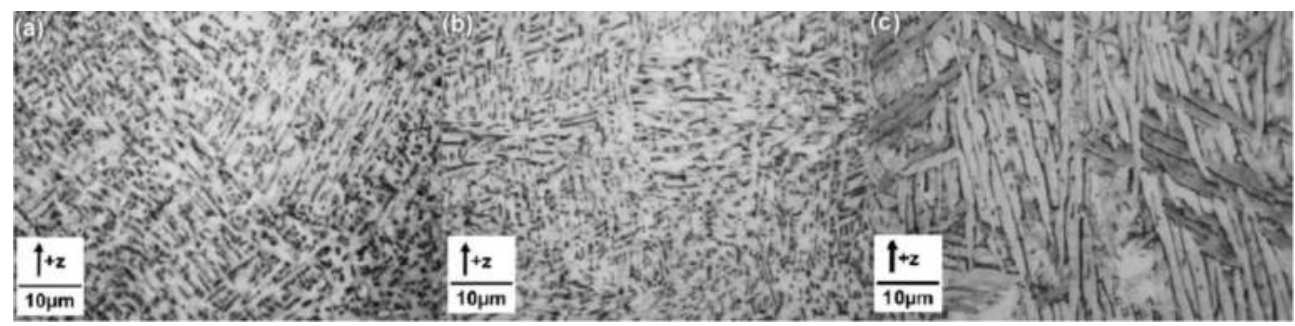

Figure 5. Optical microscope images for the (a) as-built (b) stress-relieved and (c) HIPed conditions showing expected equilibrium acicular or Widmanstatten microstructure [48].

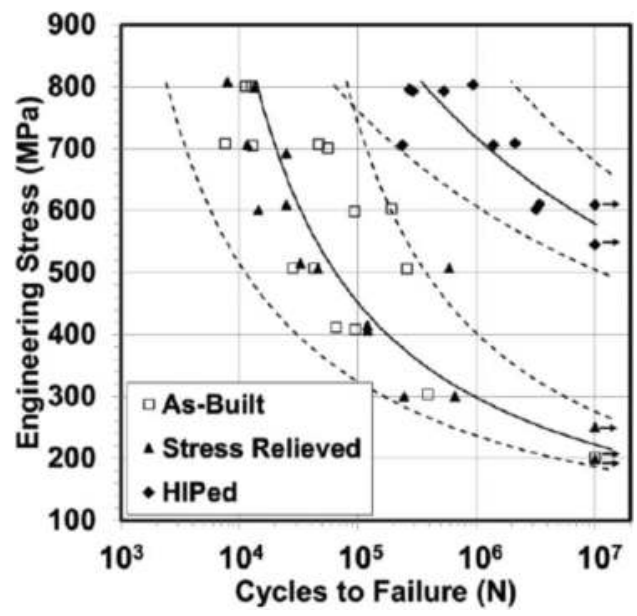

Figure 6. S-N curve fatigue results for all three conditions [48]. 
Wang et al. [50] successfully fabricated Ti-6Al-4V by laser additive manufacturing with the aim of investigating the build direction on microhardness and Tribology behavior. The phase analyses of the fabricated samples obtained by XRD revealed alpha, alpha martensite and beta, which is uncharacteristic of the conventional phases found in typical Ti-6Al-4V which are alpha + beta phases co-existing. The peak microhardness value was obtained on the vertically built sample and the same sample displayed best wear resistance improvement at higher applied loads. Authors also pointed out that slow cooling rates at the middle of the built samples attributed to phases responsible for high hardness in this region. This corrobates the works of Adebiyi et al. [51] and Fatoba \& Makhatha [52].

Zhao et al. [53] studied the evolution of plastic deformation and the effect it has on mechanical properties of extra low industrial Ti-6Al-4V repaired by laser additive technique. The microstructure of the laser additive manufactured samples presented a superfine microstructure within the columnar grains while the wrought substrate that the fabrication was done on displayed a Widmanstatten microstructure with coarse equiaxial grains as also reported by Adesina et al. [54]. The micro-hardness profile displays an increase of the microhardness property from the substrate toward the direction of build which is attributed to the rapid cooling rate of the molten powders. The tensile strength and ductility of the laser additive manufactured sample were both greater than that of the wrought titanium substrate; however, the opposite can be said with elongation.

Denlinger et al. [55] studied the effect of the inter-layer dwell time times (period whereby the laser is at rest) on distortion and residual stresses induced on titanium and nickel alloys during additive manufacturing. The dwell of 0,20 and $40 \mathrm{~s}$ were used for each material while keeping all other processing parameters constant. The obtained results displayed that the accumulated distortion increases with increased dwell time for Ti-6Al-4V, whereas it remained relatively constant for the nickel alloy. Furthermore, authors pointed out that majority of distortion occurred in the first two layers of the Ti-6Al-4V build, which drastically reduces with each layer and becomes more dwell time dependant. In conclusion, less distortion was attained in the Ti-6Al-4V fabricated with no dwell time and all the nickel alloys having greater distortion when compared to the Ti-6Al-4V counterparts.

\section{Conclusion}

The success of laser AM will rely on the detailed understanding of the relationship between the process parameters and the resulting material properties. This is because of the exceptionally high solidification rates caused by the unusually high laser heat input, which results in highly non-equilibrium microstructures. While these microstructures are mostly beneficial to the mechanical properties of the component, they cannot be predicted from conventional phase diagrams. It means they must be studied experimentally and numerically. Moreover, an understanding of the relationship between process parameters and material defects such as cracks, voids, inclusions and lack of fusion must be developed experimentally. Solving these problems requires new approaches to the understanding of the laser-matter interaction and the manufacturing processes of the near net shaped components. Hence, tailored parts and 
components can be manufactured, repaired, and modified by AM. Near-net-shape AM techniques offer new opportunities about a sustainable protection of (material and energy) resources due to a very high material efficiency and very low energy consumption.

\section{Author details}

Olawale Samuel Fatoba ${ }^{1 *}$, Esther Titilayo Akinlabi ${ }^{1}$ and Mamookho Elizabeth Makhatha ${ }^{2}$

*Address all correspondence to: drfatobasameni@gmail.com

1 Department of Mechanical Engineering Science, Faculty of Engineering and the Built Environment, University of Johannesburg, South Africa

2 Department of Metallurgy, Faculty of Engineering and the Built Environment, University of Johannesburg, South Africa

\section{References}

[1] Adesina OS, Popoola API, Fatoba OS. Laser surface modification - A focus on the wear degradation of titanium alloy. In: Paul M, editor. Fiber Laser. InTech; 2016. DOI: 10.5772/ 61737. Available from: http://www.intechopen.com/books/fiber-laser/

[2] Attar H, Prashanth KG, Chaubey AK, Calin M, Zhang LC, Scudino S, Eckert J. Comparison of wear properties of commercially pure titanium prepared by selective laser melting and casting processes. Materials Letters. 2015;142:38-41

[3] Froes FH, Gungor MN, Imam MA. The Minerals, Metals and Materials Society JOM. 2007;59:28-31

[4] Vrancken B, Thijs L, Kruth J-P, Van Humbeeck J. Heat treatment of Ti6Al4V produced by Selective Laser Melting: Microstructure and mechanical properties. Journal of Alloys and Compounds. 2012;541:177-185

[5] Baumer M, Dickens P, Tuck C, Hague R. The cost of additive manufacturing: Machine productivity, economies of scales and technology-push. Technological Forecasting and Social Change. 2016;102:193-201

[6] Ferdinand J-P, Petschow U, Dickel S. The Decentralized and Network Future of Value Creation: 3D Printing and its Implications for Society, Industry and Sustainable Development. City (Berlin): Springer International Publishing AG Switzerland; 2016. pp. 76-77

[7] Pinkerton AJ. [INVITED] Lasers in additive manufacturing. Optics \& Laser Technology. 2016;78:25-32

[8] Patterson AE, Messimer SL, Farrington PA. Overhanging features and the SLM/DMLS residual stresses problem: Review and future research need. Technologies. 2017;5(2):15 
[9] Hanzl P et al. The influence of processing parameters on the mechanical properties of SLM parts. Procedia Engineering. 2015;100:1405-1413

[10] Francois MM, Sun A, King WE, Henson NJ, Tourret D, Bronkhorst CA, Carlson NN, Newman CK, Haut T, Bakosi J, Gibbs JW, Livescu V, Vander Wiel SA, Clarke AJ, Schraad MW, Blacker T, Lim H, Rodgers T, Owen S, Abdeljawad F, Madison J, Anderson AT, Fattebert J-L, Ferencz RM, Hodge NE, Khairallah SA, Walton O. Modeling of additive manufacturing processes for metals: Challenges and opportunities. Current Opinion in Solid State and Material Science. 2017

[11] Vora D, Srinisvasan G, Rajamure NDR. Laser Alloyed AL-W Coatings on Aluminium for Enhanced Corrosion. Elsevier; December 2014. p. 10

[12] Bhushan B, Gupta BK. Handbook of Tribology: Materials, Coatings, and Surface Treatments; 1991

[13] de Oliveira U, Ocelik V, De Hosson JTM. Analysis of coaxial laser cladding processing conditions. Surface and Coatings Technology. 2000;197:127-136

[14] Betts JT. Practical methods for optimal control and estimation using nonlinear programming. Society for Industrial and Applied Mathematics. SIAM Review. 2010;53(1):183-185

[15] Watkins KG, McMahon MA, Steen WM. Microstructure and corrosion properties of laser surface processed aluminium alloys: A review. Journal of Material Science and Engineering. 1997;231:55-61

[16] Fatoba OS, Popoola API, Farotade GA, Pityana SL. Computational dynamics of laser alloyed metallic materials for improved corrosion performance: Computational dynamics of laser alloyed metallic materials; 2016. DOI: 10.4018/978-1-5225-03293.ch008. http:// www.igiglobal.com/chapter/computational-dynamics-of-laser-alloyed-metallic-materialsfor-improved-corrosion performance/149842

[17] Kwok CT, Cheng FT, Man HC. Cavitation erosion and corrosion behaviour of laseraluminized mild steel. Surface and Coatings Technology. 2006;200:3544-3552

[18] Fatoba OS, Popoola API, Fedotova T, Pityana SL. Electrochemical studies on the corrosion behaviour of laser alloyed Zn-Sn coatings on UNS G10150 steel in 1M HCl solution. Silicon. 2015;7(4):357-369

[19] Fagagnolo JB, Pallone E, Martin DR, Kiminami CS, Bolfarini C, Botta W. Processing of Al matrix composites reinforces with Al-Ni compounds and $\mathrm{Al}_{2} \mathrm{O}_{3}$ by reactive milling and reactive sintering. Journal of Alloys and Compounds. 2009;471:448-452

[20] Adebiyi DI, Popoola API, Pityana SL. Microstructural evolution at the overlap zones of $12 \mathrm{Cr}$ martensitic stainless steel laser alloyed with TiC. Optics and Laser Technology. 2014;61:15-23

[21] Yakovlev A, Bertrand PH, Smurov I. Laser cladding of wear resistant metal matrix composite coatings. Thin Solid Films. 2004;453:133-138 
[22] Poulon-Quintin A, Watanabe I, Watanabe E, Bertrand C. Mechanical and microstructural properties of surface treated cast titanium with Nd: YAG laser. Dental Materials. 2012;24: 2769-2783

[23] Zhou R, Sun GF, Chen KK, Tong YQ. Effect of tempering on microstructure mechanical properties of cast iron rolls laser alloyed with C-B-W-Cr. Materials Science and Engineering. 2014;62:1-7

[24] Fatoba OS, Popoola API, Pityana SL, Adesina OS. Computational dynamics of anticorrosion performance of laser alloyed metallic materials. In: Paul M, editor. Fiber Laser. InTech; 2016. DOI: 10.5772/62334. Available from: http://www.intechopen.com/books/ fiber-laser/computational-dynamics-of-anti-corrosion-performance-of-laser-alloyed-metallicmaterials

[25] Popoola API, Fatoba OS, Aigbodion VS, Popoola OM. Tribological evaluation of mild steel with ternary alloy of Zn-Al-Sn by laser deposition. International Journal of Advanced Manufacturing Technology. 2016:1-7. DOI: 10.1007/s00170-016-9170-7

[26] Xu W, Sun S, Elambasseril J, Liu Q, Brandt M, Qian M. Ti-6Al-4V additively manufactured by selective laser melting with superior mechanical properties. The Minerals, Metals \& Materials Society. 2015;67:668-673

[27] Balla VK, Sonderlind J, Bose S, Bandyopadhyay A. Microstructure, mechanical and wear properties of laser surface melted Ti6Al4V alloy. Journal of the Mechanical Behaviour of Biomedical Materials. 2014;32:335-344

[28] Brandl E, Schoberth A, Leyens C. Morphology, microstructure, and hardness of titanium (Ti-6Al-4V) blocks deposited by wire-feed additive layer manufacturing (ALM). Materials Science and Engineering A. 2012;532:295-305

[29] Makuch N, Kulla M, Dziarski P, Przestacki D. Laser surface alloying of commercially pure titanium with boron and carbon. Optics and Lasers in Engineering. 2014;57:64-81

[30] Yang Y, Guo N, Li J. Synthesizing, microstructure and microhardness distribution of Ti$\mathrm{Si}-\mathrm{C}-\mathrm{N} / \mathrm{TiCN}$ composite coating on $\mathrm{Ti}-6 \mathrm{Al}-4 \mathrm{~V}$ by laser cladding. Surface \& Coatings Technology. 2013;219:1-7

[31] Chen $\mathrm{Y}$, Wu D, Ma G, Lu W, Guo D. Coaxial laser cladding $\mathrm{Al}_{2} \mathrm{O}_{3}-13 \% \mathrm{TiO}_{2}$ powders on Ti6Al4V alloy. Surface \& Coatings Technology. 2013;228:S452-S455

[32] Weng F, Yu H, Chen C, Dai J. Microstructures and wear properties of laser cladding Cobased composite coatings on Ti-6Al-4V. Materials and Design. 2015;80:174-181

[33] Fatoba OS, Popoola O, Popoola API. The effects of silicon carbide reinforcement on the properties of $\mathrm{Cu} / \mathrm{SiCp}$ composites. Silicon. 2015;7:351-356

[34] Carroll BE, Palmer TA, Beese AM. Anisotropic tensile behavior of Ti-6Al-4V components fabricated with directed energy deposition additive manufacturing. Acta Materialia. 2015;87:309-320 
[35] Gong H, Rafi K, Gu H, Ram GDJ, Starr T, Stucker B. Influence of defects on mechanical properties of Ti-6Al-4 V components produced by selective laser melting and electron beam melting. Materials and Design. 2015;86:545-554

[36] Makhatha ME, Fatoba OS, Akinlabi ET. Effects of rapid solidification on the microstructure and surface analyses of laser-deposited Al-Sn coatings on AISI 1015 steel. The International Journal of Advanced Manufacturing Technology. 2017:1-15. https:/doi.org/ 10.1007/s00170-017-0876-y

[37] Chikarakara E, Naher S, Brabazon D. High speed laser surface modification of Ti-6Al4V. Surface \& Coatings Technology. 2012;206:3223-3229

[38] Yang J, Yang H, Yu H, Wang Z, Zeng X. Corrosion behavior of additive manufactured Ti6Al-4V alloy in $\mathrm{NaCl}$ solution. Metallurgical and Materials Transactions A. 2017. DOI: 10.1007/s11661-017-4087-9

[39] Popoola API, Fatoba OS, Popoola OM, Pityana SL. The influence of heat treatment and process parameter optimization on hardness and corrosion properties of laser alloyed X12CrNiMo steel. Silicon. 2016;8(4):579-589

[40] Farayibi PK, Folkes JA, Clare T. Laser deposition of Ti-6Al-4V wire with WC powder for functionally graded components. Materials and Manufacturing Processes. 2013;28: 514-518

[41] Mahamood RM, Akinlabi ET, Shukla M, Pityana S. Laser metal deposition of Ti6Al4V: A study on the effect of laser power on microstructure and microhardness. In: Proceedings of the International MultiConference of Engineers and Computer Scientists. Vol. II; 2013

[42] Rafi HK, Karthik NV, Gong H, Starr TL, Stucker BE. Microstructures and mechanical properties of Ti6Al4V parts fabricated by selective laser melting and electron beam melting. Journal of Materials Engineering and Performance. 2013;22:3872-3883

[43] Vrancken B, Thijs L, Kruth J-P, Van Humbeeck J. Microstructure and mechanical properties of a novel beta titanium metallic composite by selective laser melting. Acta Materialia. 2014; 68:150-158

[44] Hu T, Hu L, Ding Q. Effective solution for the tribological problems of Ti-6Al-4V: Combination of laser surface texturing and solid lubricant film. Surface \& Coating Technology. 2012;206:5060-5066

[45] Gong H, Rafi K, Gu H, Starr T, Stucker B. Analysis of defect generation in Ti-6Al-4V parts made using powder bed fusion additive manufacturing processes. Additive Manufacturing. 2014;1-4:87-98

[46] Fatoba OS, Popoola API, Aigbodion VS. Experimental study of hardness values and corrosion behaviour of laser alloyed Zn-Sn-Ti coatings of UNS G10150 mild steel. Journal of Alloys and Compounds. 2016;658:248-254

[47] Aigbodion VS, Popoola API, Fatoba OS. Evaluation of hardness values and corrosion behaviour of laser alloyed 20Al-20Sn-60Ti coatings of UNS G10150 mild steel. International 
Journal of Advanced Manufacturing Technology. 2015;81:1-11. DOI: 10.1007/s00170-0158111-1

[48] Hrabe N, Gnäupel-Herold T, Quinn T. Effects of internal defects and residual stress on fatigue properties of a titanium alloy (Ti-6Al-4V) fabricated via electron beam melting (EBM). In: World Materials Research Institutes Forum International Workshop for Young Scientists; 2016

[49] Cunningham R, Nicolas A, Madsen J, Fodran E, Anagnostou E, Sangid MD, Rollett AD. Analyzing the effects of powder and post-processing on porosity and properties of electron beam melted Ti-6Al-4V. Materials Research Letters. 2017. DOI: 10.1080/ 21663831.2017.1340911

[50] Wang $\mathrm{P}$ et al. Microstructure and mechanical properties of a newly developed low Young's modulus Ti-15Zr-5Cr-2Al biomedical alloy. Materials Science and Engineering: C. $2017 ; 72: 536-542$

[51] Adebiyi DI, Fatoba OS, Pityana SL, Popoola API. Parameters optimization, microstructure and microhardness of silicon carbide laser deposited on titanium alloy. In: Proceedings of International Conference on Surface Modification Technologies; 29th June-1st July, 2016; Milan, Italy; 2016. pp. 1-6

[52] Fatoba OS, Makhatha ME. Improved corrosion, mechanical and tribological properties of Ti6Al-4V alloy by direct laser deposition. In: Paul M, editor. Nova Science Publishers Book Chapter; 2017. https://www.novapublishers.com/catalog/product_info.php?products_ id $=62603$

[53] Zhao Z, Chen J, Tan H, Lin X, Huang W. Evolution of plastic deformation and its effect on mechanical properties of laser additive repaired Ti64ELI titanium alloy. Optics \& Laser Technology. 2017;92:36-43

[54] Adesina OS, Popoola API, Fatoba OS. Laser surface modification-A focus on the wear degradation of titanium alloy. In: Paul M, editor. Fiber Laser. InTech; 2016. DOI: 10.5772/ 61737. Available from: http://www.intechopen.com/books/fiber-laser/

[55] Denlinger ER, Heigelb JC, Michalerisb P, Palmerc TA. Effect of inter-layer dwell time on distortion and residual stress in additive manufacturing of titanium and nickel alloys. Journal of Materials Processing Technology. 2015;215:123-131 
